\title{
Clinico-Pathological Profile of Patients with Malignant Melanoma of Extremity: Short Term Single Centre Experience
}

\author{
Muktanjalee Deka ${ }^{1}$, Ashish Kumar Gupta ${ }^{2}$, Pioja Pegu ${ }^{3}$ \\ ${ }^{1}$ Associate Professor, Department of Pathology, ${ }^{2}$ Assistant Professor \& Consultant, Department of Surgical \\ Oncology, ${ }^{3}$ Post Graduate trainee, Department of Pathology, State Cancer institute, Gauhati Medical College \& \\ Hospital, Guwahati(GMCH), Assam
}

\begin{abstract}
Introductions: Malignant melanoma is a rare skin cancer in Asia but both incidence and mortality rates are increasing in last few decades.Clinical and pathological assessment of patients with malignant melanoma establishes a definite diagnosis and is important for patient prognosis and management.

Materials and Method: We present clinical and pathological profile of 14 patients with malignant melanoma of extremity presenting at State Cancer institute, GMCH from September 2018 to May 2019. Of them, 10 patients underwent wide excision of the primary lesion along with regional lymph node dissection . Rest 4 patients underwent wide excision only. Specimens were sent to the department of Pathology , GMCH for histopathological examination. Immunohistochemistry was also done.
\end{abstract}

Results : The most common site of melanoma is the lower extremity. Incidence was found to be higher in males compared to females with median age of presentation 54 years. Majority of patients are farmers or labourers. Ulceration is the most common mode of presentation. Maximum patients presented within 6 months of onset of symptoms.

Based on TNM , Clark and Breslow classification, 35.5\% $(n=5)$ were Clark stage 4, 35.5\%(n=5) were clark stage 5 which were the most common and $78.5 \%(n=11)$ were breslow stage 4 .

Conclusions: Although malignant melanoma are rare neoplasms, incidence has increased in few decades. Lymph node staging should be done in all cases even if clinically and radiologically negative. Surgery with adjuvant treatment remains the mainstay of management.

Keywords: lower extremity, Immunohistochemistry, malignant melanoma.

\section{Introduction}

Malignant Melanoma (MM) is a potentially lethal form of skin cancer. Although it accounts for only $3 \%$ to $5 \%$ of all skin cancers, it is responsible for approximately 75 percent of all skin cancer deaths ${ }^{[1]}$. The incidence increases with age, particularly in males. There is an increase in incidence according to available statistics of the incidence of skin cancers in India over a 10 year of period $^{[2]}$.

\section{Corresponding author :}

\section{Dr. Ashish Kumar Gupta,}

Assistant Professor \& Consultant, Department of Surgical Oncology, State Cancer institute, GMCH
The study was a hospital based retrospective study. We present a clinical and pathological profile of 14 patients diagnosed with malignant melanoma of extremity presenting at State Cancer Institute, GMCH from September 2018 to May 2019. Patient files and pathology reports were analysed to record age at diagnosis, gender, date of diagnosis, tumor localization and histolopathology (based on the American joint committee on cancer (AJCC) classification), Breslow's tumor thickness, Clarks's level of invasion, presence of ulceration, tumor infiltrating lymphocytes, lymphovascular invasion and perineural invasion. Out of 14 patients, 10 patients underwent wide excision of the primary tumor and inguinal-pelvic lymph node 
dissection with local reconstruction. Rest 4 underwent wide excision only. Study variables recorded were put in Table 1 and Table 2 .

\section{Results}

In our study we found that ( See Table $1 \&$ Table 2)

1. The commonest primary site was the lower exremity.

2. Incidence was found to be higher in males compared to females (11:3) with median age of presentation was 54 years.

3. Maximum patients presented within 6 months of onset of symptoms.

4. Majority of patients are farmers or labourers.

5. Ulceration is the most common mode of presentation.

6. Based on TNM, Clark's and Breslow classification, $35.5 \%(n=5)$ were Clark stage 4 , $35.5 \%(n=5)$ were Clark stage 5 which were the most common and $78.5 \%(\mathrm{n}=11)$ were breslow stage 4 .

\section{Table 1: Clinical profile}

\begin{tabular}{|c|c|}
\hline Age & $54.88 \pm 11.07 \mathrm{yrs}$ \\
\hline $\mathrm{M}: \mathrm{F}$ & $11: 3$ \\
\hline Occupation & $\begin{array}{l}\text { Farmer } n=6 \\
\text { Labourer } n=3 \\
\text { Others } n=5\end{array}$ \\
\hline MC site & $\begin{array}{l}\text { Lower extremity (All } \\
14 \text { patients) }\end{array}$ \\
\hline MC subsite & $\begin{array}{l}\text { Great toe } n=3 \\
\text { Sole } n=8 \\
\text { Heel } n=3\end{array}$ \\
\hline $\begin{array}{l}\text { Duration of } \\
\text { Symptoms }\end{array}$ & $6.3 \pm 4.92$ Months \\
\hline MC Symptom & $\begin{array}{l}\text { Ulcer in lower } \\
\text { extremity (13 } \\
\text { patients) } \\
\text { Groin nodal mass (1 } \\
\text { Patient) }\end{array}$ \\
\hline $\begin{array}{l}\text { Regional nodes } \\
\text { (Clinically detected) }\end{array}$ & $\begin{array}{l}\text { Palpable: } n=6 \\
\text { Non-palpable: } n=8\end{array}$ \\
\hline $\begin{array}{l}\text { Regional nodes } \\
\text { (Detected on } \\
\text { imaging) }\end{array}$ & $\begin{array}{l}\text { Enlarged: } n=7 \\
\text { Not Enlarged: } n=7\end{array}$ \\
\hline
\end{tabular}

\section{Table 2: Pathological profile}

\begin{tabular}{|c|c|}
\hline Breslow thickness & $\begin{array}{l}<1 \mathrm{~mm} \mathrm{n}=0 \\
1-2 \mathrm{~mm} \mathrm{n}=2 \\
2-4 \mathrm{~mm} \mathrm{n}=1 \\
>4 \mathrm{~mm} \mathrm{n}=11\end{array}$ \\
\hline $\begin{array}{l}\text { Clarke's level of } \\
\text { invasion }\end{array}$ & $\begin{array}{l}\text { Clarke } 1 n=0 \\
\text { Clarke } 2 n=3 \\
\text { Clarke } 3 n=5 \\
\text { Clarke } 4 n=5 \\
\text { Clarke } 5 n=1\end{array}$ \\
\hline Ulcer & $\begin{array}{l}\text { Present: } n=11 \\
\text { Absent } n=3\end{array}$ \\
\hline $\begin{array}{l}\text { Tumor infiltrating } \\
\text { lymphocytes }\end{array}$ & $\begin{array}{l}\text { Present } n=11 \\
\text { Absent } n=3\end{array}$ \\
\hline $\begin{array}{l}\text { Lympho vascular } \\
\text { invasion }\end{array}$ & $\begin{array}{l}\text { Present } n=5 \\
\text { Absent } n=9\end{array}$ \\
\hline Peri neural invasion & $\begin{array}{l}\text { Present } n=4 \\
\text { Absent } n=10\end{array}$ \\
\hline Groin Nodes & $\begin{array}{l}\text { Positive }=6 \\
\text { Negative }=4\end{array}$ \\
\hline Pelvic nodes & $\begin{array}{l}\text { Positive }=3 \\
\text { Negative }=7\end{array}$ \\
\hline
\end{tabular}

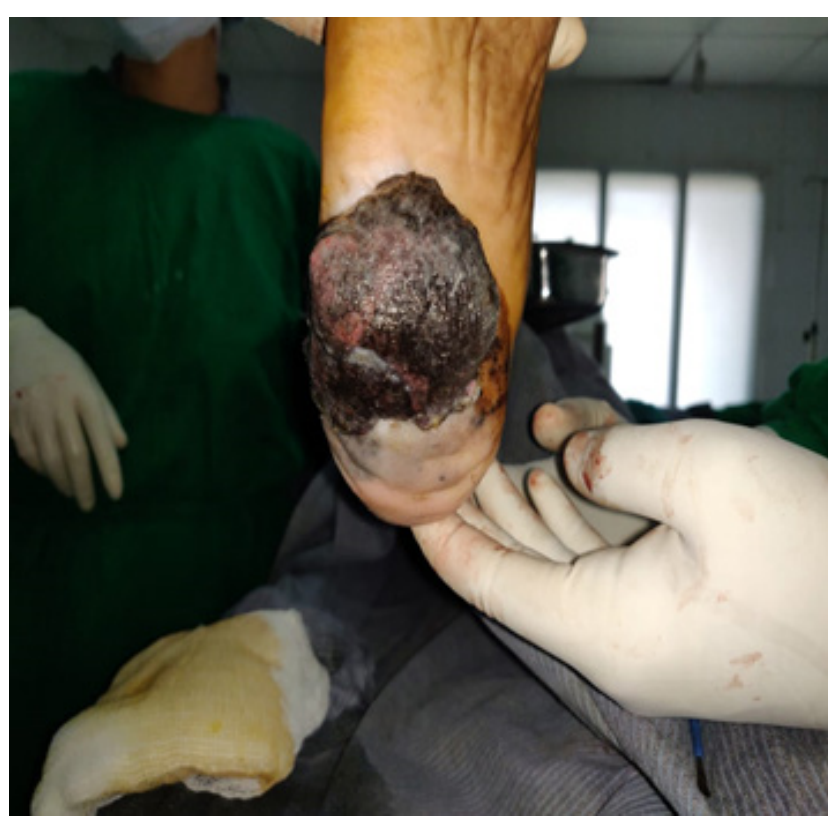

Fig 1: Clinical appearance of melanoma showing a large pigmented and ulcerated lesion in the sole of foot. 


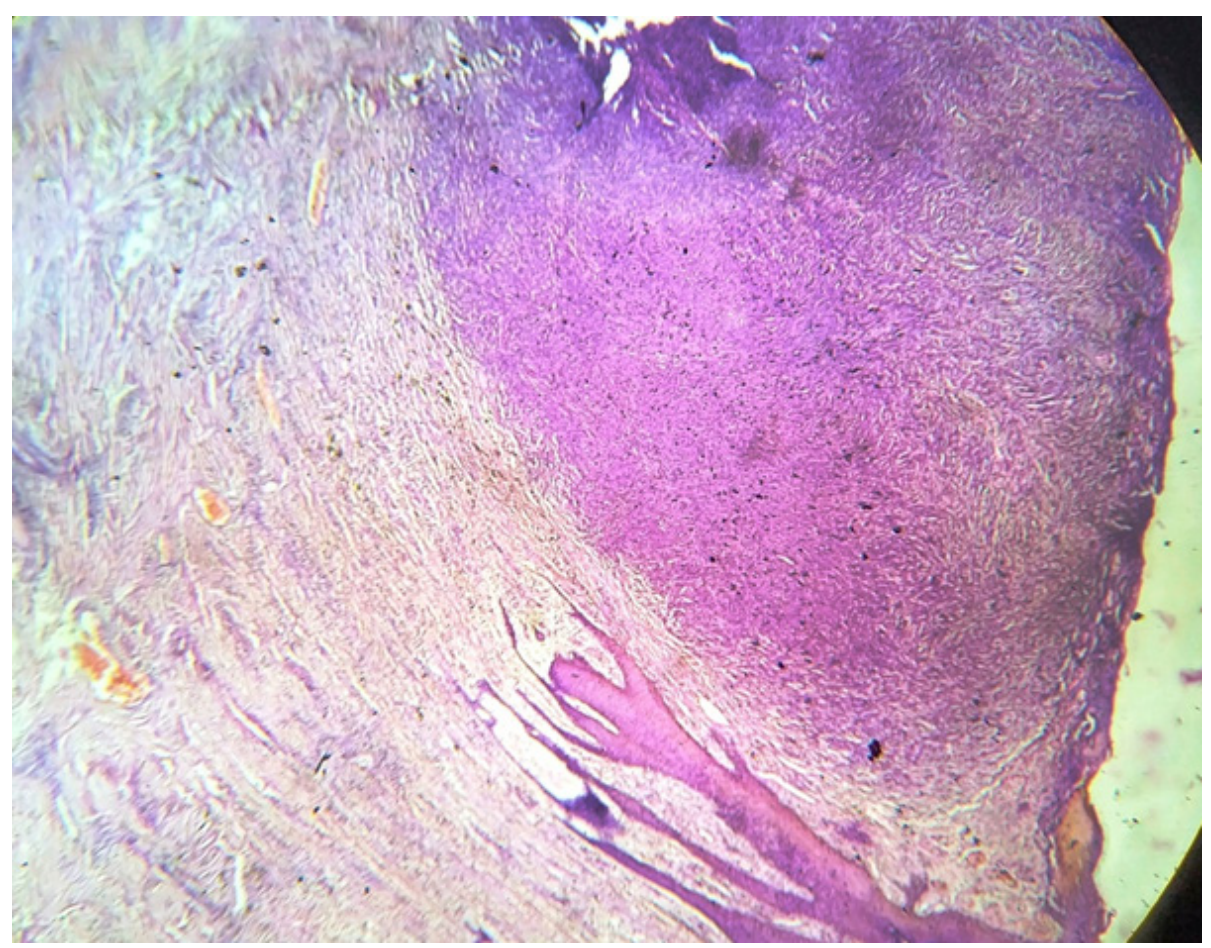

Fig 2 : Malignant melanocytes invades upto the dermis (Clark's level 2)

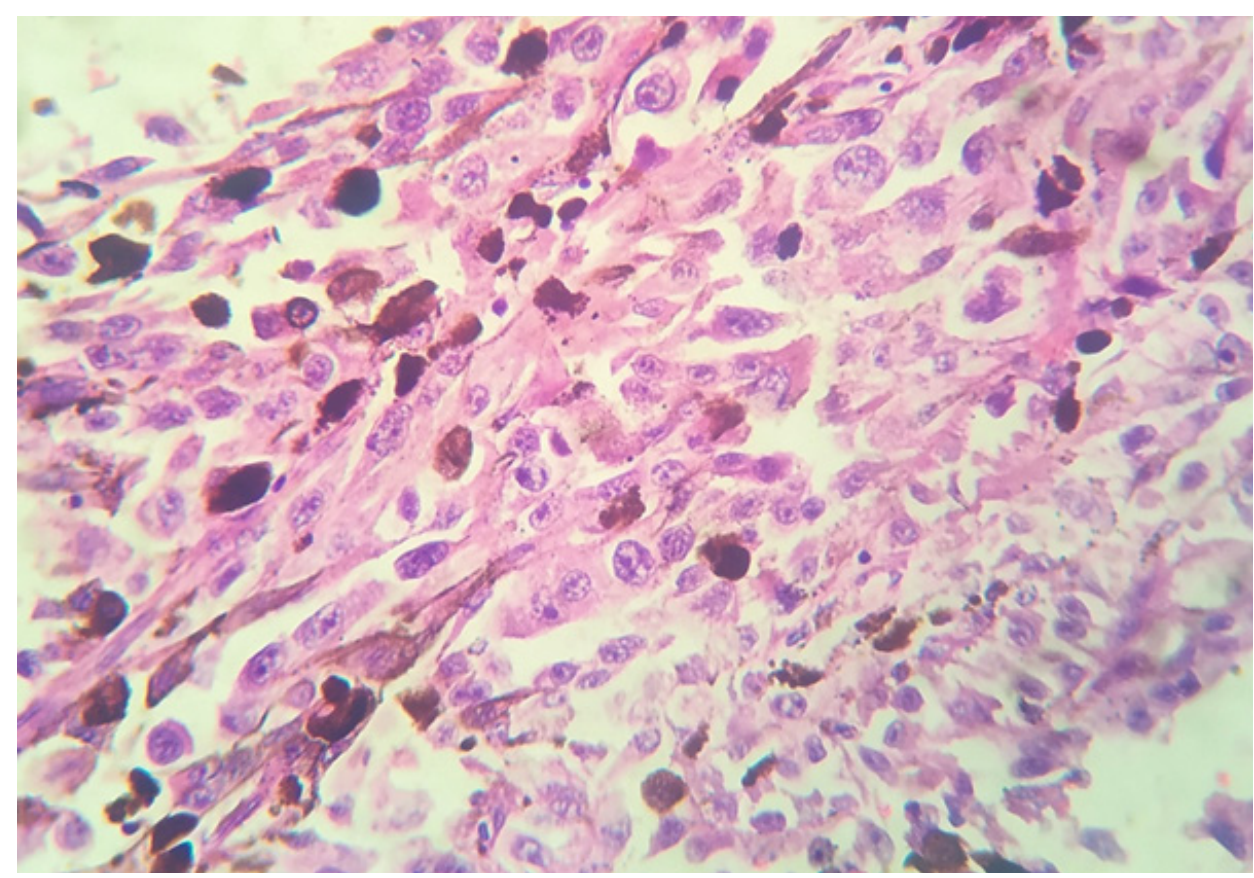

Fig 3: Melanoma showing epithelioid malignant cells. 


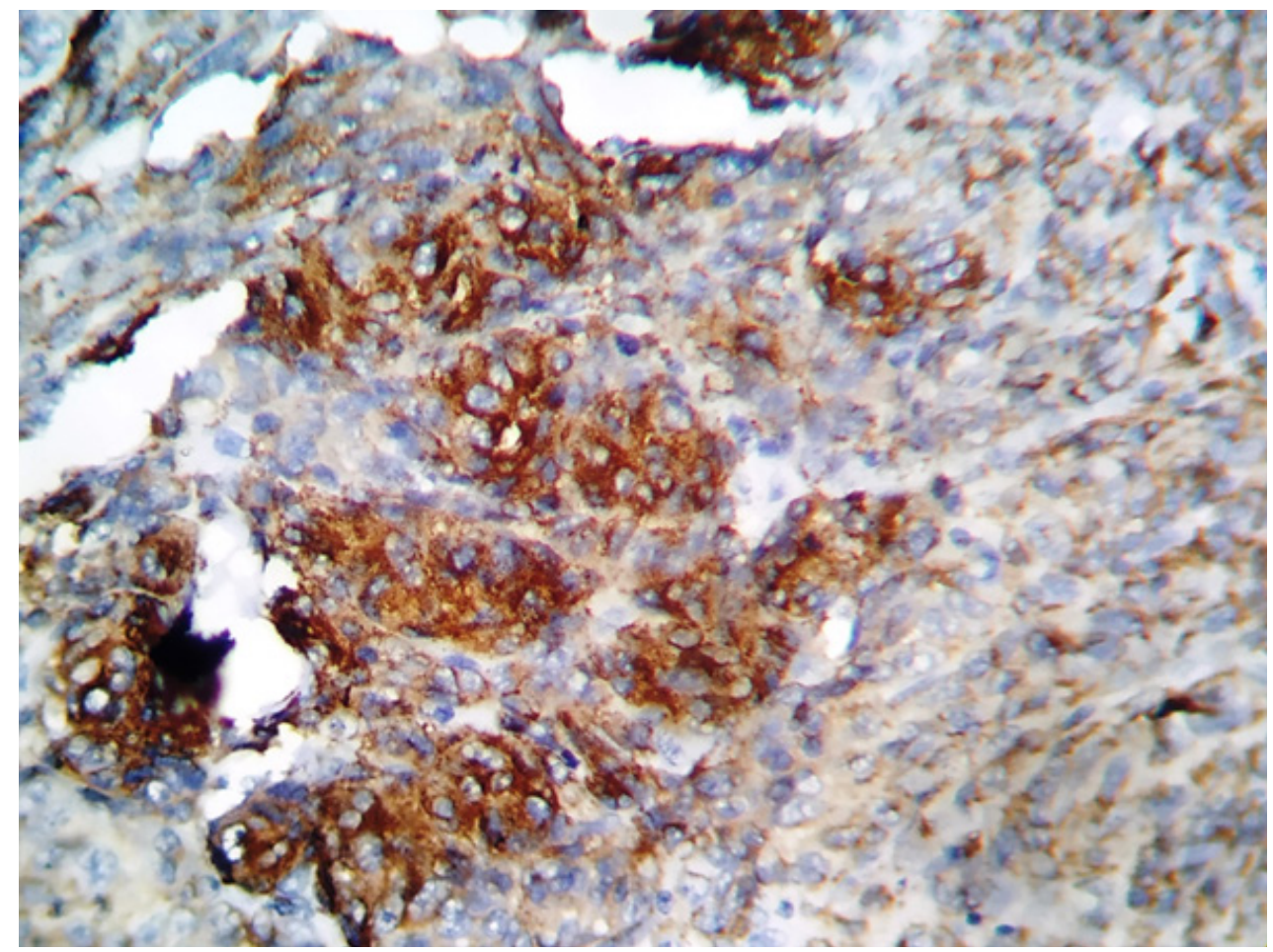

Fig 4 : Immunoreactive for HMB 45

\section{Discussion}

Melanoma is a deadly form of skin cancer derived from pigment producing melanocytes[3,4,5]. Some lesions like amelanocytic melanoma are hard to diagnose. "ABCD" (Asymmetry, irregular border, uneven colour , diameter $>6 \mathrm{~mm}$ ) is considered the standard approach for the clinical diagnosis of malignant melanoma.

Histopathology is the gold standard for diagnosis of melanoma. The malignant cells can be epitheliod (figure 3)or spindle shaped (figure 2). Breslow's thickness is the strongest predictor of survival. Other attributes are Clark's level of invasion, ulceration, presence of tumorinfiltrating lymphocytes,mitotic activity, regression, vascular invasion, peri-neural invasion, and microscopic satellites.

Immunochemistry has only a very limited role. The typical melanoma is reactive for $\mathrm{S}-100, \mathrm{HMB}-45$, tyrosinase, MiTF, and SOX10.

The mainstay of treatment for melanoma is surgical excision, with optimal margins being determined by the depth of the tumor( breslow thickness) along with chemotherapy and immunotherapy. Total lymph node dissection should be performed following the identification of nodal diseases by Sentinal lymph node biopsy. In our study, none of the patients received chemotherapy or immunotherapy.

Study done by Jina A and et al(2017) found that in melanoma patients, ulcer was the commonest mode of presentation, $60 \%$ patients were farmers and daily labourers with history of increased exposure to sunlight, incidence was more for males than females. The highest incidence of skin cancer was in the 5 th to 7 th decade of life[6].

Study done by Sula b et al(2016) found male (56.4\%) preponderance,median age of presentation was 62.50 years, most common tumor localization was the lower extremitis and given the patient distribution based on the clark and breslow staging, the most common were clark stage 4 and $37.1 \%$ were breslow stage $4[7]$.

Study done by Chi Z, Li S et al (2011) found that $65.5 \%$ of melanoma patients had ulceration[8].

Study done by Johnson-Obaseki S E et al(2015) showed that Melanoma incidence is increasing in Canada and is higher among people in high SES groups. This rise is likely due to increases in sun exposure[9].

Study done by Cherobin ACFP et al (2018) showed that Male gender, Breslow thickness $>4 \mathrm{~mm}$ and the 
presence of ulceration were considered risk factors for the occurrence of metastasis in patients with primary cutaneous melanoma[10].

Study done by EVRENOS M K et al(2018) found that The ages of patients ranged between 18 and 80 (mean: 59.9). 33 of the tumors were Clark 4 (50.8\%), and 12 of the tumors were Clark $5(18.5 \%)$. Thirty $(46.1 \%)$ of the tumors had ulceration[11].

Our study correlates with above mentioned studies.

\section{Conclusions}

Melanoma is an aggressive tumor with high mortality when diagnosed in advanced stages. Its incidence is increasing drastically all over the world, as well as its cases of death[12,13].Lymph node staging should be done in all cases even if clinically and radiologically negative. Early detection of melanoma is associated with better prognosis and outcome. Adjuvant treatment remains a challenge due to high costs associated with immunotherapy and targeted therapy.

Conflict of Interest : There are no conflicts of interest

\section{Source of Funding : Self}

Ethical Clearance : Not taken as it was a retrospective observational study. Data has been collected from medical records and no intervention has been made in the treatment of patients.

\section{References}

1. Sladden, M.J.; Balch, C.; Barzilai, D.A.; Berg, D.; Freiman, A.; Handiside, T.; Hollis, S.; Lens, M.B.; Thompson, J.F. Surgical excision margins for primary cutaneous Melanoma. Cochrane Database Syst. Rev. 2009, doi:10.1002/14651858.

2. National Cancer Registry Programme (NCRP). Bienneal report. Indian Council of Medical Research; 1995-2005.

3. National Cancer Institute. SEER Stat Facts Sheet: Melanoma of the Skin. Accessed August 23, 2016.

4. Goldenberg A, Vujic I, Sanlorenzo M, et al.
Melanoma risk perception and prevention behavior among African-Americans: the minority melanoma paradox. Clin Cosmet Investig Dermatol 2015;8:423-9.

5. Guy GPJr, Thomas CC, Thompson T, et al. Vital signs: melanoma incidence and mortality trends and projections: United States, 1982- 2030. MMWR Morb Mortal Wkly Rep 2015;64:591-6.

6. Jina A, Singh V, Saini S, Chotan N, Rajan M. Clinicopathological profile, diagnosis and treatment of skin cancers at a tertiary care center: a retrospective study. Int Surg J 2017;4:2549-55.

7. Sula B,Ucmak F, Kaplan A M, Urakci Z, Arica M, Isikdogan A : Epidemiological and clinical characteristics of malignant melanoma in southeast Anatolia in Turkey. Pan Afr Med J.2016 May 6; $24: 22$

8. Chi et al.: Clinical presentation, histology, and prognoses of malignant melanoma in ethnic Chinese: A study of 522 consecutive cases. BMC Cancer 2011 11:85.

9. Johnson-ObasekiS E, Labajian V, Corsten M J, McDonald J T. Journal of Otolaryngology - Head and Neck Surgery(2015) 44:53

10. Cherobin ACFP, Wainstein AJA, Colosimo EA, Goulart EMA, Bittencourt FV. Prognostic factors for metastasis in cutaneous melanoma. An Bras Dermatol. 2018;93(1):19-26.

11. EVRENOS $\mathrm{M} \mathrm{K}$, TEMIZ P,ÇAM $\mathrm{F} \mathrm{S}$, YAMAN M, YOLERI L, ERMERTCAN A T : Clinicopathological characteristics and mutation profile of BRAF and NRAS mutation in cutaneous melanomas in the Western Turkish population. Turk J Med Sci (2018) 48: 973-979.

12. Balch CM, Gershenwald JE, Soong SJ, Thompson JF, Atkins MB, Byrd DR, et al. Final version of 2009 AJCC melanoma staging and classification. J Clin Oncol. 2009;27:6199-206.

13. Inca.gov.br [Internet]. Instituto Nacional do Câncer. Tipos de Câncer: Pele Melanoma. Rio de Janeiro: INCA; 2012. [acesso 21 jun 2012]. 